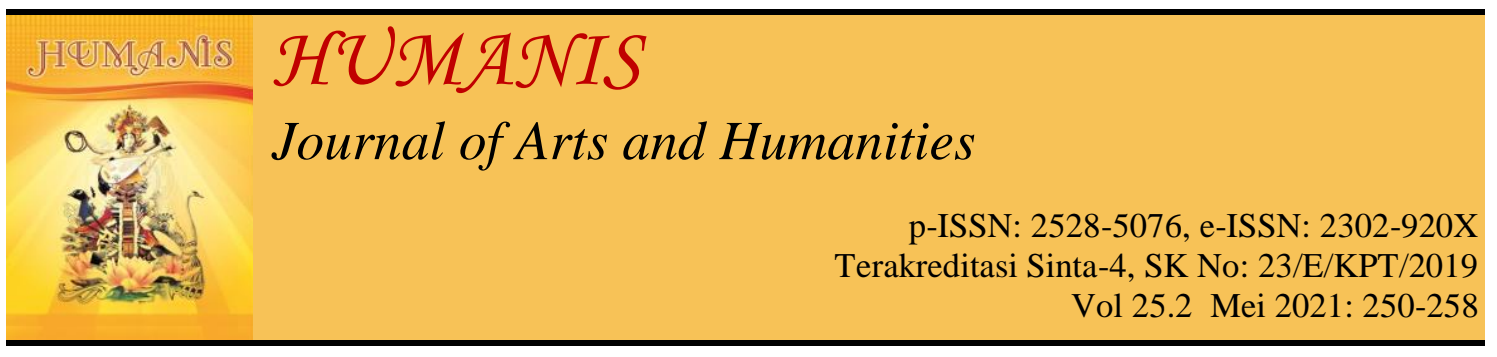

\title{
Kesetaraan Hak Warga Kolok sebagai Wujud Integrasi Sosial Warga Desa Bengkala
}

\author{
Chrisantya Angelita
}

Universitas Udayana, Denpasar, Bali, Indonesia

Email korespondensi: chrisantyaangelitar@gmail.com

\begin{tabular}{l}
\hline Info Artikel \\
\hline Masuk:31 Maret 2021 \\
Revisi:20 Mei 2021 \\
Diterima:24 Mei 2021 \\
Keywords: \\
equality rights, kolok villager, \\
social integrity \\
\\
Kata kunci: \\
kesetaraan hak, warga kolok, \\
integrasi sosial \\
Corresponding Author: \\
Chrisantya Angelita \\
Email: \\
chrisantyaangelitar@gmail.co \\
m \\
DoI: \\
https://doi.org/10.24843/JH.20 \\
21.v25.i02.p14 \\
\end{tabular}

\section{PENDAHULUAN}

Berdasarkan Kamus Besar Bahasa Indonesia (2016), hak diartikan sebagai kekuasaan untuk berbuat sesuatu karena telah ditentukan oleh undang-undang, aturan, dan sebagainya. Pada dasarnya semua orang mempunyai hak, sebab hak adalah sesuatu yang seseorang terima sejak ia lahir. Namun kenyataannya

\begin{abstract}
Deaf mute villager in Bengkala village is called as kolok villager. In Bengkala Village, kolok villager as disabled community is not getting discriminated by society. This research intend to study about equality rights for kolok villager in Bengkala Village. Theory used in this study is Functionalism Structural Talcott Parsons. The research method are interview and observation. The result shows that kolok villager are accepted by Bengkala Village society. Because basically normal villager and kolok villager are related. The equality rights are art right, education right, economy right, and voting right.

\begin{tabular}{l}
\hline Abstrak \\
\hline Warga tuli bisu Desa Bengkala disebut dengan warga \\
kolok. Di Desa Bengkala warga kolok sebagai kaum \\
disabilitas tidak mengalami diskriminasi di masyarakat. \\
Penelitian ini bermaksud untuk mengkaji kesetaraan hak \\
warga kolok di Desa Bengkala. Teori yang digunakan \\
dalam penelitian ini adalah teori Fungsionalisme \\
Structural Talcott Parsons. Metode penelitian yang \\
dilakukan yaitu wawancara dan observasi. Hasil \\
penelitian menunjukkan bahwa warga kolok diterima di \\
masyarakat Desa Bengkala. Karena pada dasarnya \\
warga kolok dan warga normal adalah kerabat. \\
Kesetaraan hak yang didapatkan warga kolok yaitu hak \\
kesenian, hak pendidikan, hak ekonomi, dan hak suara.
\end{tabular}
\end{abstract}

terjadi ketidaksetaraan hak di masyarakat. Ketidaksetaraan ini disebabkan oleh klasifikasi sosial. Pada klasifikasi sosial kelompok disabilitas kesulitan mendapatkan haknya. Pada kasus kelompok disabilitas, orang dengan keterbatasan fisik masih sulit untuk mendapatkan pekerjaan. Maka dari itu kesetaran hak kelompok disabilitas 
diperjuangkan agar kelompok disabilitas dapat setara.

Terdapat 43 warga tuli bisu di Desa Bengkala. Warga tuli bisu di Desa Bengkala disebut dengan warga kolok. Michi (2017) menyatakan fenomena ini disebabkan oleh perkawinan endogami lokal yang dipraktikkan dari generasi ke generasi pada populasi kecil. Alhasil, warga kolok tersebar di 14 dadia (klan) Desa Bengkala. Dalam kehidupan bermasyarakat, warga kolok bergaul dengan warga normal. Tidak ada diskriminasi yang warga kolok alami, sebab itu warga kolok menerima hak yang sama dengan warga normal.

Di Desa Bengkala, warga kolok mendapat kesempatan yang setara dengan warga normal. Hal ini jarang ditemukan di masyarakat pada umumnya. Warga kolok mendapat hak yang sama dengan warga normal di berbagai bidang. Di bidang kesenian, Sekaa Janger Kolok merupakan wadah bagi warga kolok yang gemar menari tari janger. Di bidang pendidikan, terdapat SD $\mathrm{N} 2$ Desa Bengkala yaitu fasilitas sekolah inklusi bagi warga kolok. Di bidang ekonomi, warga kolok mendapat kesempatan bekerja yang sama dengan warga normal. Di bidang lain, warga kolok mempunyai hak berpendapat. Warga kolok dilibatkan dalam pertemuan rapat desa agar dapat menyampaikan aspirasi. Warga kolok juga mempunyai hak pilih dalam pemilihan umum.

Berdasarkan latar belakang tersebut, rumusan permasalahan yang penulis kedepankan dalam penelitian ini yaitu bagaimana kesetaraan hak warga kolok di Desa Bengkala sebagai wujud integrasi sosial?

\section{METODE DAN TEORI}

Sumber data penelitian terdiri atas data primer dan data sekunder. Menurut Harnovisah (2019), data primer yaitu data yang diperoleh dari informan langsung di lapangan, sedangkan yang dimaksud dengan data sekunder yakni data yang diperoleh melalui sumber yang sudah ada. Data primer diperoleh melalui wawancara dengan pihak yang berhubungan langsung dengan warga kolok Desa Bengkala, antara lain kepala desa dan pembina paguyuban warga kolok. Data sekunder didapat dari studi pustaka, dokumentasi yang berkaitan, dan sumber internet.

Pengumpulan data dilakukan melalui observasi, wawancara, dan studi pustaka. Observasi merupakan suatu penyelidikan menggunakan kemampuan indera manusia yang dilakukan secara sistematis (Endraswara, 2012). Pada tahap pengumpulan data, peneliti mengamati kehidupan dan interaksi warga kolok di Desa Bengkala. Selain itu, wawancara adalah cara mengumpulkan keterangan tentang kehidupan manusia dalam suatu masyarakat yang dilakukan secara lisan melalui percakapan tatap muka dengan seorang informan (Koentjaraningrat, 1983). Data juga didapat melalui studi pustaka sebagai referensi acuan penelitian dan kerangka teoretis.

Pada tahap awal penelitian, peneliti terlebih dahulu melakukan kajian pustaka dengan menelaah beberapa referensi yang berkaitan dengan topik penelitian. Referensi yang menjadi acuan penelitian ini berupa skripsi yang bertajuk "Adaptasi Kehidupan Penyandang Tuli Bisu di Desa Bengkala Kecamatan Kubutambahan Kabupaten Buleleng" oleh Suteja. Penelitian Suteja (1996) mengungkapkan mekanisme adaptasi warga kolok dalam berbagai aspek kehidupan. Pada aspek ekonomi warga kolok bekerja di sektor pertanian, kemudian warga kolok turut terlibat dalam kegiatan mengayah di pura dan keamanan desa. Pada aspek kesenian sebagai warga kolok terlibat dalam Sekaa Janger Kolok.

Penelitian Sudiastuti (2005) yang berjudul "Interaksi Sosial Warga Tuli Bisu (Kolok) di Desa Bengkala 
Kecamatan Kubutambahan, Kabupaten Buleleng" menyatakan warga kolok menggunakan bahasa isyarat lokal yang berbeda dengan daerah lainnya yakni bahasa kolok. Bahasa kolok mengisyaratkan kode yang terbagi menjadi beberapa macam yaitu kode menunjukkan pekerjaan, menunjukkan situasi dan kondisi, menunjukkan barang atau orang, serta kode menunjukkan status atau keadaan. Kode ini digunakan warga kolok berkomunikasi dalam menjalani aktivitasnya yaitu terlibat dalam sistem ayahan pura, sistem keamanan, juga kesenian yaitu Tari Janger Kolok.

Konsep integrasi sosial dijabarkan dalam Fungsionalisme Struktural yang diperkenalkan Talcott Parsons. Pada teori Fungsionalisme Struktural, Parsons mengasumsikan bahwa pada dasarnya masyarakat berada dalam sebuah sistem sosial yang mengikat mereka dalam keseimbangan (ekuilibrium). Hal ini tercermin dari dua pengertian dasar integrasi sosial yaitu, pertama, pengendalian terhadap konflik dan penyimpangan sosial dalam suatu sistem sosial tertentu, dan kedua, menyatukan unsur-unsur tertentu dalam suatu masyarakat sehingga tercipta sebuah tertib sosial (Ritzer, 2016).

Dalam teorinya Talcott Parsons mengedepankan konsepnya yang disebut AGIL. Adaptation (adaptasi), sistem harus mengatasi kebutuhan situasional dengan cara menyesuaikan lingkungan dengan kebutuhan-kebutuhannya. Goal attainment (Pencapaian tujuan), yaitu sistem harus menegaskan dan berupaya mencapai tujuannya. Integration (Integrasi), yaitu sistem harus mengatur hubungan yang menjadi komponennya yaitu adaptation, goal attainment, dan latency. Terakhir yaitu Latency (Latensi/pemeliharaan pola) di mana sistem harus memelihara motivasi individu dan pola-pola budaya yang menciptakan dan mempertahankan motivasi tersebut (Afifa dan Sari, 2019).

\section{HASIL DAN PEMBAHASAN}

Setiap individu mempunyai hak dan kewajiban individu masing-masing. Hak adalah sesuatu yang berhak diterima oleh seseorang, sedangkan kewajiban adalah sesuatu yang wajib untuk ditunaikan. Hak merupakan sesuatu yang individu terima sejak lahir dan tidak bisa dicabut dari individu tersebut. Namun dalam dinamika masyarakat terdapat ketidaksetaraan perihal pemenuhan hak individu. Ketidaksetaraan yang nampak mencolok di masyarakat yaitu ketimpangan hak antara warga normal dan warga disabilitas. Ketidaksetaraan ini disebabkan oleh anggapan bahwa warga disabilitas tidak setara dengan warga normal. Warga disabilitas dianggap tidak mampu untuk berfungsi dengan baik seperti warga normal. Anggapan tersebut tidak tepat dan tentunya merugikan warga disabilitas untuk dapat berkembang.

Suparlan (2011) menyatakan kesetaraan warga dan hak budaya komuniti adalah unsur-unsur mendasar yang ada dalam prinsip demokrasi, yang menekankan pentingnya hak individu dan kesetaraan individu atau warga, dan toleransi terhadap perbedaan dan keanekaragaman. Pernyataan Suparlan dapat disimpulkan bahwa kesetaraan hak individu adalah bagian dari penerapan demokrasi di masyarakat. Pemerintah memang sudah mengupayakan kesetaraan hak warga disabilititas dengan adanya jaminan hukum, namun upaya tersebut belum optimal. Basuki (2012) dan Rahayu dan Dewi (2013) menyatakan kelompok disabilitas masih kesulitan mendapatkan pelayanan publik dan kesehatan, kesempatan untuk berpartisipasi di bidang politik, mendapatkan pekerjaan, perlindungan hukum, dan akses pendidikan 
Sistem sosial merupakan interaksi antara dua individu atau lebih dalam satu lingkungan tertentu, maupun interaksi antara kelompok dengan kelompok. Parsons mengemukakan syarat agar sistem dapat bekerlanjutan. Sistem harus terstruktur dan mampu harmonis dengan sistem lain. Selain itu, sistem harus mampu mengendalikan ancaman atau pun konflik. Oleh karena itu sekalipun proses integrasi sosial tidak bisa terjadi dengan sempurna, namun secara fundamental sistem sosial selalu cenderung bergerak ke arah ekuilibrium yang bersifat dinamis. Proses tersebut dilalui dengan penyesuaian-penyesuaian dan tidak terjadi secara singkat. Faktor tepenting untuk mencapai integrasi sosial adalah konsensus atau mufakat di masyarakat mengenai nilai-nilai kemasyarakatan tertentu (Turama, 2018).

Desa Bengkala sering disebut desa kolok atau desa tuli bisu. Sebutan tersebut disebabkan karena terdapat 43 warga kolok yang tinggal di Desa Bengkala. Desa Bengkala terdiri atas 2 banjar dan 14 dadia, warga kolok tersebar di 14 dadia tersebut. Warga kolok mampu beradaptasi meskipun kesulitan untuk mendengar dan berbicara. Warga kolok berkomunikasi menggunakan bahasa kolok. Warga normal di Desa Bengkala secara umum sudah memahami bahasa kolok. Maka dari itu, bahasa kolok membantu warga kolok berinteraksi dengan sekitarnya.

Dikutip dari website Desa Bengkala (2017), visi dari Desa Bengkala adalah "Prima dalam Pelayanan Mengembangkan Potensi Sumber Daya Manusia (SDM) Agar Berdaya Saing dalam Era Milenial berdasar Tri Hita Karana". Visi tersebut mencermikan tujuan yang ingin dicapai di Desa Bengkala. Pemberdayaan tersebut mencakup seluruh warga Desa Bengkala termasuk warga kolok. Untuk mencapai visi tersebut Desa Bengkala merangkul warga kolok melalui beberapa pertemuan.
Ada pun pertemuan tersebut dikemas dalam bentuk focus group discussion (FGD). Pertemuan dilakukan secara intensif, sehingga mendorong proses integrasi Desa Bengkala terhadap warga kolok.

Perselisihan lumrah terjadi dalam proses interaksi dan seringkali menjadi konflik. Apa bila timbul konflik yang melibatkan warga kolok, konflik tersebut diselesaikan secara kekeluargaan. Penyelesaian konflik tersebut ditengahi oleh Bapak I Komang Wisnu selaku pembina warga kolok. Menurut Bapak I Komang Wisnu, biasanya konflik yang timbul disebabkan karena miskomunikasi (Angelita, 2021). Selain penanggulangan konflik, latensi juga diterapkan dengan tidak mendiskriminasi warga kolok. Warga normal berbaur dengan warga kolok dalam bermasyarakat. Sebab pada dasarnya warga normal dan warga kolok saling bersaudara. Integrasi sosial di Desa Bengkala terwujud karena adanya pedoman hidup yaitu menyama braya.

Menyama braya merupakan salah satu ajeg Bali yang artinya 'aku adalah engkau dan engkau adalah aku'. Menyama braya merupakan filosofi masyarakat Bali untuk mengasihi sesama seperti mengasihi diri sendiri demi terciptanya perdamaian. Menyama braya mengajarkan individu akan banyak hal, seperti berkomunikasi dan berinteraksi untuk membangun persaudaraan yang kuat. Menyama braya dipercaya sebagai wujud kemenangan dharma (Basyir, 2016). Penerapan menyama braya memupuk rasa solidaritas di Desa Bengkala. Rasa solidaritas menyadarkan warga Desa Bengkala atas pemenuhan hak warga kolok. Kesetaraan hak warga kolok di Desa Bengkala terdapat di berbagai bidang yaitu di bidang kesenian, pendidikan, ekonomi.

\section{Hak Kesenian}

Tari Janger Kolok adalah tari profan yang lahir di Desa Bengkala, Buleleng. 
Tari ini dipertunjukkan oleh Sekaa Janger Kolok atau kelompok penari janger kolok di Desa Bengkala. Tari Janger Kolok adalah variasi tari pergaulan Bali yaitu tari janger yang diciptakan oleh Alm. Bapak Nedeng agar bisa dipentaskan oleh warga kolok.

Sekaa Janger Kolok berdiri sejak tahun 1967. Tari Janger Kolok diajarkan langsung oleh Bapak Nedeng, yang kebetulan bisa berkomunikasi menggunakan bahasa kolok. Proses pembelajaran gerakan tari berjalan cukup lama yaitu 3-5 bulan. Hal tersebut wajar terjadi, terlebih lagi warga kolok belum ada yang pernah belajar menari sama sekali. Namun warga kolok tetap antusias belajar menari. Pada awalnya, gerakan tari Janger Kolok adalah gerakan tari Janger umumnya yang menampilkan gerakan tari Kecak. Gerakan itu juga dikolaborasikan dengan gerakan pencak silat yang menggunakan senjata tajam. Dalam perkembangannya terdapat perubahan koreografi pada tari Sekaa Janger Kolok sehingga gerakan pencak silat tidak lagi ditampilkan.

Tari Janger Kolok biasanya dipentaskan pada acara-acara hiburan. Sekaa Janger Kolok pertama kali pentas di acara yang digelar oleh saudara Alm. Bapak Nedeng. Acara tersebut digelar di kediaman saudara Alm. Bapak Nedeng yang beralamatkan di Jagaraga. Saat itu akses jalan menuju Jagaraga masih sulit yaitu menyebrangi sungai dan tebing. Belum ada transportasi yang bisa mengantar, sehingga perjalanan menuju Jagaraga ditempuh hanya dengan berjalan kaki. Di awal perkembangannya, Sekaa Janger Kolok belum diupah seperti sekarang. Sebagai ganti upah, warga kolok hanya diberikan konsumsi. Lama kelamaan kabar keberadaan Sekaa Janger Kolok semakin meluas beredar. Sekaa Janger Kolok sudah pernah tampil di berbagai acara nasional bahkan internasional (Angelita, 2021).
Payuyasa (2016) menyatakan keberadaan Sekaa Janger Kolok memberi warna baru yang unik dalam sejarah seni budaya di Bali. Sebelumnya warga kolok tidak diperhitungkan dalam melestarikan kebudayaan. Salah satu apresiasi untuk Sekaa Janger Kolok yaitu kesempatan untuk pentas dalam acara Pesta Kesenian Bali 2002. Pemerintah membantu perkembangan Sekaa Janger Kolok sebagai wujud kepedulian terhadap budaya lokal. Perkembangan tersebut dapat dilihat dari pakaian penari yang lebih modern. Dalam perkembangannya antusias warga terhadap Sekaa Janger Kolok terus meningkat (Pertiwi, 2014). Tari Janger Kolok menunjukkan potensi warga kolok di bidang seni. Potensi warga kolok juga dikembangkan melalui KEM, di sana warga kolok diajarkan beberapa variasi tarian baru. Di samping tari Janger Kolok, sekarang warga kolok bisa menampilkan tari Baris Bebek Bingar Bengkala (Baris Bebila), tari Jalak Anguci, dan tari Puspa Arum Bengkala.

\section{Hak Ekonomi}

Kegiatan ekonomi di Desa Bengkala didominasi oleh sektor pertanian. Warga kolok secara umum bekerja di sektor pertanian di Desa Bengkala, sama seperti warga normal. Keterampilan becocok tanam sudah ditekuni warga kolok selama bertahun-tahun. Selain bercocok tanam, ada pun warga kolok yang berdagang, bekerja sebagai tukang pijat, kuli bangunan, membuat sesajen, dan lainlain. Renawati (2017) menyatakan pada dasarnya warga kolok sudah bisa memenuhi kebutuhan hidup sehari-hari, namun masih perlu arahan agar semakin berdaya. Atas pertimbangan tersebut maka didirikan Kawasan Ekonomi Masyarakat (KEM) di Desa Bengkala.

KEM tersebar di berbagai wilayah Indonesia dan saat ini jumlahnya mencapai sebanyak 32 KEM. KEM Bengkala dinaungi oleh FlipMAS 
Ngayah Bali dan secara resmi berdiri sejak 2013. Bangunan KEM dibangun dengan fasilitas pendukung pemberdayaan warga kolok. Di KEM Bengkala terdapat kandang ternak, dan kebun yang menanam berbagai tanaman pangan. Sistem peternakan yang diterapkan di KEM Bengkala yaitu zero waste integrated farming, yakni sistem peternakan dengan pengelolaan limbah agar tidak mencemari lingkungan. Jadi, limbah dari hewan ternak yaitu sapi, babi, dan ayam diproses agar dapat digunakan sebagai bahan bakar untuk memasak (Renawati, 2017).

Pemberdayaan warga kolok di KEM tidak hanya pertanian dan peternakan, warga kolok juga mendapat pembinaan tenun, pembuatan kue, dan pembuatan jamu. Kain tenun yang dihasilkan oleh warga kolok di KEM menjadi kain tenun khas dari Desa Bengkala. Kain tenun khas tersebut mempunyai motif kuda laut. Pembuatan kue ditekuni oleh warga kolok perempuan. Aneka kue yang dibuat beragam bahan dasarnya yaitu singkong, ubi, dan tepung terigu. Saat ini warga kolok memasarkan sendiri kue yang diproduksi ke pasar dan toko sekitar Desa Bengkala. Pembuatan jamu di KEM Bengkala berbahan dasar kunyit yang banyak diproduksi di Desa Bengkala.

\section{Hak Pendidikan}

Mencerdaskan bangsa adalah salah satu cita-cita negara yang tertuang dalam Pembukaan UUD 1945. Pemerataan pendidikan di seluruh negeri telah diupayakan pemerintah, termasuk di Desa Bengkala. Pendidikan adalah dasar pengembangan sumber daya manusia untuk meningkatkan kesejahteraan masyarakat. Ada pun upaya yang telah dilakukan yaitu pengadaan sekolah inklusi di Desa Bengkala. SD No. 2 Bengkala merupakan sekolah inklusi di Desa Bengkala. Marentek menyatakan yang dimaksud dengan pendidikan inklusi adalah pelayanan pendidikan bagi peserta didik yang mempunyai kebutuhan pendidikan khusus di sekolah regular (SD, SMP, SMA, Dan SMK) yang tergolong luar biasa baik dalam arti kelainan, lamban belajar (slow learner) maupun yang kesulitan belajar lainnya (Darma dan Rusyidi, 2015). SD No. 2 Bengkala sebagai pemenuhan hak pendidikan untuk warga kolok yang bertujuan agar warga kolok tidak tertinggal di bidang pendidikan. Kegiatan belajar mengajar diajarkan oleh tenaga pendidik yang mampu berkomukasi menggunakan bahasa isyarat.

SD No. 2 Bengkala dibuka pada 1 Januari 1978 di Desa Bengkala. Pada awal dibuka sekolah ini dikepalai oleh I Wayan Wita dengan 3 orang tenaga pendidik dan 8 orang peserta didik. Jumlah peserta didik sangat sedikit karena terhambat faktor ekonomi, dan warga Bengkala cenderung memilih agar anak-anaknya membantu bekerja di ladang daripada belajar di sekolah. Maka dari itu, Bapak Wisnu dan Bapak Kanta berinisiatif mengajarkan anak-anak Desa Bengkala dari rumah ke rumah. Di awal 2000-an SD No. 2 Bengkala jumlah peserta didik mulai bertambah sebanyak 8 hingga 15 orang, dan sekarang kegiatan belajar tidak lagi dikenai biaya pendidikan. SD No. 2 Bengkala secara teknis telah menyediakan pendidikan formal bagi anak-anak kolok sejak 2003. Namun SD No. 2 Bengkala secara resmi menjadi sekolah inklusi pada tahun 2007. Sekolah ini diresmikan sebagai sekolah inklusi bagi peserta didik berkebutuhan khusus golongan B yakni peserta didik yang tuli bisu. SD No. 2 Bengkala terbuka bagi anak-anak tuli bisu dari luar Bengkala dan anak-anak dengan keterbatasan yang lain.

Saat ini terdapat 18 peserta didik tuli bisu yang duduk di bangku SD No. 2 Bengkala dengan 10 orang tenaga pendidik dan satu orang pengabdi yakni Bpk. Wisnu. Kurikulum yang diterapkan yaitu K13. Kurikulum K13 menekankan 
kompetensi inti antara lain sikap dan spriritual, sikap sosial, pengetahuan dan keterampilan. Pada tahun pertama sekolah, peserta didik sekolah inklusi diajari kemampuan dasar membaca, menulis, berhitung dan bahasa isyarat umum. Selanjutnya jika sudah dinyatakan mampu melakukan kemampuan dasar tersebut, peserta didik dapat lanjut ke kelas 2 (Yani, 2020).

\section{Hak Berpendapat, dan Hak Memilih}

Hak warga negara untuk bebas berpendapat dijamin oleh negara. Di Desa Bengkala, pemenuhan hak tersebut terdapat pada saat diadakan pertemuan desa. Warga kolok juga diikutsertakan dalam pertemuan atau rapat desa dan diberikan kesempatan untuk menyampaikan aspirasi. Hal ini merupakan pengakuan pemerintah setempat atas aspirasi yang berasal dari warga kolok.

Selain hak berpendapat setiap warga negara juga berhak untuk memilih dan dipilih. Untuk saat ini belum ada warga kolok yang maju dalam pemilih pemimpin wilayah setempat, namun warga kolok bisa memilih dalam pemilihan umum. Andika dkk (2018) menyatakan warga kolok dapat menggunakan hak pilihnya dalam Pilkada Serentak 2017. Bahkan tingkat partisipasi warga kolok dalam Pilkada Serentak 2017 mencapai 100\%. Tidak hanya berpartisipasi sebagai pemilih, warga kolok juga terlibat sebagai panitia dalam pemungutan suara.

\section{SIMPULAN}

$\begin{array}{rlr}\text { Warga } & \text { disabilitas } & \text { seringkali } \\ \text { mengalami } & \text { ketidakadilan } & \text { dalam }\end{array}$ pemenuhan haknya. Padahal pemenuhan hak warga disabilitas sudah dijamin oleh negara. Pemandangan berbeda ditemukan di Desa Bengkala. Di Desa Bengkala terdapat 43 warga tuli bisu atau kolok. Warga kolok tidak mengalami diskriminasi. Di Desa Bengkala warga kolok mendapatkan hak yang sama dengan warga normal Desa Bengkala. Kesetaraan hak warga kolok terdapat di pemenuhan pada bidang kesenian, pendidikan, ekonomi, dan politik. Warga kolok pertama kali mendapatkan hak kesenian setelah adanya Sekaa Janger Kolok. Di bidang pendidikan terdapat sekolah inklusi yaitu SD No. 2 Bengkala. Pada bidang ekonomi, mayoritas warga kolok bekerja di sektor pertanian dan perekonomian warga kolok semakin berkembang setelah adanya KEM Bengkala. Warga kolok turut dilibatkan dalam pengambilan keputusan di desa Bengkala, selain itu warga kolok dapat menggunakan hak pilihnya saat pilkada atau pemilu. Saran untuk penelitian berikutnya adalah penelitian mengenai pemenuhan hak kelompok disabilitas di desa lain di Bali, agar dapat mendorong pemenuhan hak warga disabilitas yang adil khususnya di Bali.

\section{DAFTAR PUSTAKA}

Afifa, I. D. K, \& Sari, M. M. K. (2019). Proses Integrasi Sosial Masyarakat Multietnik di Desa Sumbertanggul Kecamatan Mojosari Kabupaten Mojokerto. Kajian Moral Kewarganegaraan, 07(02), 1346 - 1360.

Andika, R. F., Noak, P. A., Bandiyah. (2018). Desa Bengkala Dan Pemenuhan Hak Politik Dalam Pemilu (Studi Kasus Kaum Disabilitas Desa Bengkala Dalam Pemilukada 2017). Politika Udayana, 1(1).

Angelita, C. (2021). Eksistensi Sekaa Janger Kolok di Desa Bengkala, Buleleng, Bali. Denpasar: Universitas Udayana.

Basuki, U. (2012). Perlindungan HAM dalam Negara Hukum Indonesia: 
Studi Ratifikasi Konvensi Hakhak Disabilitas (Convention on The Rights of Persons with Disabilities). SOSIO-RELIGIA, 10(1), 17-34.

Basyir, K. (2016). Membangun Kerukunan Antarumat Beragama berbasis Budaya Lokal Menyama Brayadi Denpasar Bali. Religió: Jurnal Studi Agama-agama, 6(2), 186-206.

Darma, I. P., \& Rusyidi, B. (2015). Pelaksanaan Sekolah Inklusi Di Indonesia. Prosiding Penelitian dan Pengabdian Kepada Masyarakat, 2(2), 147-300.

Desa Bengkala. 2017. http://bengkalabuleleng.desa.id/index.php/first/ar tikel/22a

Endraswara, Suwardi. (2012). Metodologi Penelitian Kebudayaan. Yogyakarta: Gadjah Mada University Press.

Harnovisah. (2019). Metodolgi Penelitian. Jakarta : Universitas Mercu Buana.

Kementrian Pendidikan dan Kebudayaan. (2016). Kamus Besar Bahasa Indonesia https://kbbi.kemdikbud.go.id/entri $\underline{\text { hak }}$

Koentjaraningrat. (1983). MetodeMetode Penelitian Masyarakat. Jakarta: Gramedia.

Michi, S. A. (2017). Analisis Genealogi \& Mean Matrimonial Radius Populasi Tuli-Bisu di Desa Bengkala, Buleleng, Bali. AntoUnairDotNet, 6(2), 213-222.
Payuyasa, I N. (2016). Eksistensi dan Perspektif Nilai Moral Janger Kolok di Desa Bengkala Singaraja. https://www.isidps.ac.id/artikel/eksistensi-danperspektif-nilai-moral-jangerkolok-di-desa-bengkala-singaraja/

Pertiwi, N. N. M. A. (2014). Perkembangan Sekaa Janger Kolok di Desa Bengkala, Kubutambahan, Buleleng Periode 1998-2011. Widya Winayata: Junal Pendidikan Sejarah, 2(1).

Rahayu, S \& Dewi, U. (2013). Pelayanan Publik Bagi Pemenuhan Hak-Hak Disabilitas Di Kota Yogyakarta. Jurnal Natapraja Kajian Ilmu Administrasi Negara, 1(1).

Renawati, P. W. (2017). KEM Pertaminaflip Eksistensi KEM Bengkala Singaraja-Bali Ditinjau dari Aspek Kebudayaan. UNES Journal of Community Service, 2(1).

Ritzer, George. (2016). Sosiologi Ilmu Pengetahuan Berparadigma Ganda. Rajawali Press: Jakarta.

Sudiastuti, Putu. (2005). Interaksi Sosial Warga Tuli bisu (kolok) Di Desa Bengkala Kecamatan Kubutambahan, Kabupaten Buleleng. Denpasar: Jurusan Antropologi Fakultas Sastra Universitas Udayana.

Suparlan, P. (2011). Simposium Internasional Antropologi ke-2 Kesetaraan Warga Dan Hak Budaya Komuniti Dalam Masyarakat Majemuk Indonesia. Jurnal Antropologi Indonesia.

Suteja, I M. D. (1996). Adaptasi Kehidupan Penyandang Tuli Bisu 


\section{di Desa Bengkala Kecamatan \\ Kubutambahan Kabupaten \\ Buleleng. Denpasar: Jurusan \\ Antropologi Fakultas Sastra \\ Universitas Udayana.}

Turama, A. R. (2018). Formulasi Teori Fungsionalisme Struktural Talcott Parsons. Eufoni Journal of Language, Literary and Cultural Studies, 2(2), 58-69.

Yani, N. K. T. M. (2020). Pemberdayaan Anak Tuli Bisu dalam Pendidikan Inklusi di Desa Bengkala, Kecamatan Kubutambahan, Kabupaten Buleleng, Bali. Denpasar: Universitas Udayana. 